\title{
Does the panic attack activate the hypothalamic-pituitary-adrenal axis?
}

\author{
FREDERICO G. GRAEFF ${ }^{1}$, CYBELE GARCIA-LEAL ${ }^{1}$, CRISTINA M. DEL-BEN ${ }^{1}$ \\ and FRANCISCO S. GUIMARÃES ${ }^{2}$ \\ ${ }^{1}$ Departmento de Neurologia, Psiquiatria e Psicologia Médica \\ Hospital das Clínicas da Faculdade de Medicina de Ribeirão Preto, Universidade de São Paulo \\ Avenida Bandeirantes 3900, 14048-900 Ribeirão Preto, SP, Brasil \\ ${ }^{2}$ Departmento de Farmacologia, Faculdade de Medicina de Ribeirão Preto, Universidade de São Paulo \\ Avenida Bandeirantes 3900, 14049-900 Ribeirão Preto, SP, Brasil \\ Manuscript received on March 3, 2005; accepted for publication on March 7, 2005; \\ contributed by FrEDERICO G. GRAEFF*
}

\begin{abstract}
A bibliographic search has been performed in MEDLINE using cortisol and panic as key-words, occurring in the title and/or in the abstract. Human studies were selected, with no time limit. The following publications were excluded: review articles, case reports, panic attacks in disorders other than panic disorder, and studies on changes that occurred in-between panic attacks. The results showed that real-life panic attacks as well as those induced by selective panicogenic agents such as lactate and carbon dioxide do not activate the hypothalamicpituitary-adrenal (HPA) axis. Agonists of the colecystokinin receptor B, such as the colecystokinin-4 peptide and pentagastrin, increase stress hormones regardless of the occurrence of a panic attack and thus, seem to activate the HPA axis directly. The benzodiazepine antagonist flumazenil does not increase stress hormones, but this agent does not reliably induce panic attacks. Pharmacological agents that increased anxiety in both normal subjects and panic patients raised stress hormone levels; among them are the $\alpha_{2}$-adrenergic antagonist yohimbine, the serotonergic agents 1-(m-chlorophenyl) piperazine ( $\mathrm{mCPP})$ and fenfluramine, as well as the psychostimulant agent caffeine. Therefore, the panic attack does not seem to activate the HPA axis, in contrast to anticipatory anxiety.
\end{abstract}

Key words: stress hormones, panic attack, anxiety.

\section{INTRODUCTION}

Starting with Hans Selye's (1936) seminal work, a wealth of reported evidence established that different kinds of physical or psychological conditions that threaten the organism homeostasis elicit a stereotyped set of reactions named by Selye the "general adaptation syndrome". Most characteristic is the release of the adrenocorticotropic hormone (ACTH) and corticoids (cortisone in the rat and cor-

* Member Academia Brasileira de Ciências Correspondence to: Prof. Frederico G. Graeff

E-mail: fgraeff@keynet.com.br tisol in humans) into the blood stream as a result of activation of the hypothalamic-pituitary-adrenal (HPA) axis. The stimuli or contexts that trigger the general adaptation syndrome have been named stressors and the organism response, the stress reaction. Acute stress also activates the sympathetic nervous system, including the adrenal medulla, as part of Walter Cannon's (1914) "emergency response". As a result, catecholamines are released both locally, in different tissues (noradrenaline) and in the blood circulation (mainly adrenaline).

Stressors may be physical, such as excessive 
heat or cold, tissue damage, etc., but may also be of psychological nature, among which stand those that bring about anxiety. Indeed, the results of a large number of studies have consistently shown that the sympathetic nervous system and the HPA axis are activated by either novelty or environmental cues that signal the withholding of an expected reward (frustration) or the delivery of punishment and therefore, generate anticipatory anxiety (Mason 1975).

For psychological stressors, the neural circuits mediating neuroendocrine responses involve cortical activation of the basolateral amygdala, which in turn activates the central nucleus of the amygdala. The central amygdala then activates hypothalamic neurons directly, indirectly through the bed nucleus of the stria terminalis, and/or via circuits involving brainstem serotonergic and catecholaminergic neurons. Neurons of the hypothalamic paraventricular nucleus secrete the corticotropic releasing hormone (CRH) into the portal circulation of the pituitary gland. Reaching the anterior pituitary, $\mathrm{CRH}$ stimulates ACTH-secreting cells that release ACTH into the blood stream. ACTH acts on the adrenal cortex promoting cortisol secretion and release into the blood circulation. In addition to ACTH, prolactin is consistently released from the anterior pituitary in stressful situations. Although the primary function of this hormone is to promote lactation in pregnant females, it is also considered as a stress hormone (van de Kar and Blair 1999).

Stress hormones are adaptive in the short run, but become harmful if they are in excess or persist when no longer needed. As a consequence, they are likely to participate in the pathophysiology of several medical diseases as well as psychiatric disorders (McEwen 2000).

One of the most stressful anxiety disorders is panic disorder (PD), as classified by the Diagnostic and Statistical Manual (DSM IV, APA 1994) and by the International Classification of Diseases (ICD 10, WHO 1992). The critical event of PD is the repeated occurrence of the panic attack (PA), which is a sudden and unexpected surge of extreme fear accom- panied by major neurovegetative changes, which lasts for about $20 \mathrm{~min}$. As a consequence, worry about having another attack becomes persistent, and avoidance of places where an attack would be embarrassing may gradually ensue. The extreme form of avoidance is known as agoraphobia, in which case the patient is afraid of leaving home unaccompanied, becoming incapacitated for most social requirements.

To have a PA is to undergo an overwhelming experience. The main symptoms of the PA are: fear of death or becoming crazy, sweating, palpitation or tachycardia, tremor, shortness of breath or asphyxia, thoracic pain, nausea or abdominal discomfort, de-realization or de-personalization, and cold or hot waves (APA 1994). Apparently, nothing could be more stressful. Yet, it is not certain whether the HPA axis is activated by the PA.

To help clarifying this issue, we have done a systematic survey of the literature about HPA activity in the PA, the results of which are presented in the following.

\section{MATERIALS AND METHODS}

A MEDLINE search has been made using the keywords cortisol and panic present in the title and/ or the abstract, in human subjects only, and with no time limit. From the obtained abstracts, several publications were excluded on the basis of the following criteria: review articles, case reports, stress hormones measured during the quiescent period inbetween attacks, disorders other than PD or healthy subjects not compared to PD patients. As a result, 50 articles were obtained. For discussion, some references outside the above criteria have been included.

\section{REPORTED RESULTS AND DISCUSSION}

The best way to answer the question of whether the PA activates the HPA axis or not would be to measure circulating stress hormones - cortisol, ACTH, prolactin - or salivary cortisol before and after a reallife PA. However, this task is very difficult to accomplish, since the occurrence of a spontaneous PA is 
unpredictable. In the only study found in the literature (Bandelow et al. 2000), the patients themselves were requested to collect samples of salivary cortisol, and an increase in cortisol was found. However, this result may reflect anticipatory anxiety, because the patients got prepared to collect the sample only when they felt a PA was going to happen. Indeed, the results of Bandelow et al. (2000) show that the cortisol level was already high at the beginning of the PA.

A way around this difficulty is to study PA that can be induced at will by exposing the patient to a phobic situation. With this procedure, Woods et al. (1987) reported no increase in plasma cortisol after a PA. A similar result has been reported by Cameron et al. (1987) in patients lying on their beds in a psychiatric ward since, paradoxically, relaxation and sleep favor the occurrence of PA (for a discussion, see Deakin and Graeff 1991 and Graeff 2004).

In summary, two out of three studies on real-life PA failed to show activation of HPA axis, while in the study that evidenced HPA activation this outcome may be due to anticipatory anxiety.

Because of the difficulty in exploring the reallife PA, it is no wonder that most reported studies on stress hormones made use of experimental PA. The PA can be induced in the laboratory by administering a variety of chemical substances ranging from sodium lactate to caffeine, or by inhalation of carbon dioxide at a higher concentration than in the atmosphere. The results of these investigations are presented in the following sections, divided according to the panic-inducing agent.

\section{SODIUM LACTATE}

Panic patients have higher circulating levels of lactic acid than healthy controls after exertion, a condition that often triggers PA. On this basis, Pitts and McClure (1967) conducted the first controlled study with sodium lactate infusion. They found that 13 out of 14 patients with anxiety neurosis (nowadays PD) had symptoms of an anxiety (panic) at- tack, while only 2 out of 10 healthy controls presented the same symptoms. All patients reported that the lactate-induced anxiety was similar to a reallife PA. The susceptibility of PD patients to lactate became well established by large-scale controlled studies that were performed with PD patients diagnosed on the basis of DSM III (APA 1980) criteria. The results of these studies have shown that lactate induced PA in $60-80 \%$ of panic patients as compared to $0-20 \%$ of healthy controls. They have further shown that lactate did not cause PA in patients with social anxiety disorder (SAD) and obsessivecompulsive disorder (OCD), although some patients with generalized anxiety disorder (GAD) were susceptible to lactate. Finally, pharmacological studies have evidenced that antidepressant treatment that was effective in reducing PA rate in PD patients also decreased their vulnerability to lactate (for reviews, see Bourin et al. 1998, Griez and Schruers 1998). These data thoroughly validate lactate infusion as an experimental model of PA.

In our bibliographic search we found ten studies that used lactate infusion to study stress hormones in PA. All of them compared PD patients with healthy controls and used the same dose of sodium lactate $-10 \mathrm{ml} / \mathrm{kg}$ of a $0.5 \mathrm{M}$ concentration solution given through the intra-venous route.

However, there were some procedural differences among the studies. In those by Liebowitz et al. (1985), Hollander et al. (1989) and Levin et al. (1987) a control injection of saline solution was lacking. In five studies, isotonic saline (Carr et al. 1986, Kellner et al. 1995, 1998, Seier et al. 1997, Coplan et al. 1998) was used. In another study (Peskind et al. 1998), hypertonic saline was added as control for a possible osmotic effect of the lactate solution; surprisingly, infusion of $25 \%$ sodium chloride solution induced as many PA as sodium lactate. In the study by Carr et al. (1986), there was an additional group of patients treated with the antipanic agent alprazolam. Finally, Targum (1992) compared lactate infusion and oral fenfluramine in 12 panic patients who responded positively to both challenges and 8 non-reactive controls. 
In all these studies plasma cortisol was assayed as index of HPA functioning. In addition, ACTH was measured in four studies (Levin et al. 1987, Kellner et al. 1995, 1998, Peskind et al. 1998) and prolactin in two of them (Liebowitz et al. 1985, Carr et al. 1986). With the exception of the first study (Liebowitz et al. 1985), the same instrument (Acute Panic Inventory) was used to identify the PA.

In spite of these methodological differences, the results of these studies are very coherent. In general, stress hormones were not increased, independently of whether a PA occurred or not. As an exception, an increase in plasma prolactin has been recorded in two studies (Liebowitz et al. 1985, Carr et al. 1986). Also, a non-significant trend towards an increase in plasma cortisol after a PA has been reported by Liebowitz et al. (1985) and Hollander et al. (1989). Overall, these results indicate that the HPA axis is not activated by the lactate-induced PA. It is worth remarking that Coplan et al. (1998) reported a rise in cortisol in the period preceding lactate infusion in PD patients who had PA, thus in correlation with anticipatory anxiety.

Interestingly, the PA induced by hypertonic saline solution also did not increase stress hormones (Peskind et al. 1998), a finding that points to the importance of hypernatremia in the triggering of PA. Hypernatremia releases the atrial natriuretic hormone (ANH), a peptide produced by the mio-endocrine cells of the cardiac atrium, hypothalamus and locus coeruleus (LC). ANH inhibits HPA axis activation by $\mathrm{CRH}$, preventing HPA activation during the PA induced by hypertonic saline solution (Kellner et al. 1992). Moreover, it has been reported that patients vulnerable to lactate have lower basal levels of ANH than those not having PA, but show a faster increase in ANH concentration after lactate infusion (Kellner et al. 1995, 1998, Seier et al. 1997). As a consequence, Kellner et al. (1998) have proposed that this sharp increase in ANH would explain why lactate-induced PA also does not activate the HPA axis. The same authors have further suggested that ANH could further impair HPA stimulation indirectly by inhibiting vasopressin release, since this peptide is known to enhance the CRH action on pituitary ACTH-secreting cells (Antoni 1993).

Finally, it is worth mentioning that Maddock et al. (1991) have shown that hyperventilation following glucose ingestion increased serum lactate in PD patients who panicked (7 out of 12) to a greater extent than in non-panicking patients (5) or healthy controls (12); the lactate response was significantly correlated with peak ratings of anxiety and panic symptoms, but not correlated with cortisol levels.

\section{CARBON DIOXIDE $\left(\mathrm{CO}_{2}\right)$}

The panicogenic action of $\mathrm{CO}_{2}$ inhalation in concentration higher than that normally present in the atmosphere was accidentally discovered by Gorman et al. (1984), while studying the effects of voluntary hyperventilation in panic patients. To compensate for the hyperventilation-induced alkalosis in a control group, these workers increased the concentration of $\mathrm{CO}_{2}$ to $5 \%$ in the breathing air. Surprisingly, the hypercapnic mixture induced PA while hyperventilation, per se, was ineffective. This finding originated the $5 \% \mathrm{CO}_{2}$ challenge model of PA, which is the continuous breathing of air containing $5 \%$ of the gas for $10-20 \mathrm{~min}$ or to the point of panic. In most studies the gas mixture has been administrated through a breathing mask, although sometimes a canopy has been used.

Another $\mathrm{CO}_{2}$ model of PA consists of a single vital-capacity inhalation of a mixture containing $35 \% \mathrm{CO}_{2}$ and $65 \%$ oxygen. This model also started with an unexpected observation made by van den Hout and Griez (1984). Based on previous claims associating hyperventilation and the consequent alkalosis with anxiety, the procedure was expected to reduce anxiety. Instead, symptoms similar to a PA appeared within seconds from $\mathrm{CO}_{2}$ inhalation and lasted for 30-60 sec.

Although there is large variation in the reported results, probably due to methodological differences, such as in mode of gas administration, diagnostic criteria for panic and psychometric instruments, they consistently show that PD patients are more 
vulnerable to the $\mathrm{CO}_{2}$ challenge than healthy controls as well as patients with GAD, OCD, SAD and animal phobia patients. The exception is situational phobia, a condition which is known to consistently induce PA (see above). Reported results have additionally shown that the sensitivity of PD patients to $\mathrm{CO}_{2}$ is attenuated by antipanic drug treatment (for a review, see Griez and Schruers 1998). Therefore, $\mathrm{CO}_{2}$ inhalation meets the criteria for a reliable experimental model of PA.

The similarities between lactate and $\mathrm{CO}_{2}$ induced PA led to the hypothesis that both challenges have a common mechanism of action. In this regard, Klein (1993) has suggested that the two panicogens cause intraneuronal hypercapnia in brain areas that are stimulated by $\mathrm{CO}_{2}$ during suffocation, the sensitivity of such suffocation alarm system being abnormally heightened in PD patients.

We found four studies on the HPA axis and $\mathrm{PA}$ with $\mathrm{CO}_{2}$ being used as a panicogenic agent. In three of them (Woods et al. 1988, Sasaki et al. 1996, Sinha et al. 1999) the $5 \% \mathrm{CO}_{2}$ challenge was used, while in the fourth (van Duinen et al. 2004) single inhalation of $35 \% \mathrm{CO}_{2}$ was employed. Woods et al. (1988) and Sinha et al. (1999) used a canopy to administer two $\mathrm{CO}_{2}$ concentrations, 5 and $7.5 \%$ in the first one, and 5 and $7 \%$ in the second study. Sasaki et al. (1996) used only the $5 \% \mathrm{CO}_{2}$ concentration administered through a breathing mask. In all cases plasma cortisol was assayed as index of HPA functioning.

The results of the three studies with the 5\% $\mathrm{CO}_{2}$ challenge consistently show that no significant increase in cortisol was observed after the PA. Actually, in the study by Sinha et al. (1999) there was a significant decrease in plasma cortisol in PD patients that had a PA, as compared to both healthy controls and patients who did not panic with $\mathrm{CO}_{2}$, while a non-significant trend towards a cortisol increase was detected by Woods et al. (1988) following the PA. The last authors also measured plasma prolactin, and found no increase after the PA.

A recent study conducted by van Duinen et al. (2004) has been explicitly designed to test the hypothesis of whether $\mathrm{CO}_{2}$-induced PA activates the HPA axis. A $35 \% \mathrm{CO}_{2}$ challenge was applied to 23 PD patients and 20 healthy controls, and salivary cortisol was measured before and after the challenge. Although the increase in anxiety indices determined by $\mathrm{CO}_{2}$ inhalation was far more pronounced in patients than in controls, in neither group salivary cortisol was significantly increased.

Altogether, the reported results indicate that the PA induced by $\mathrm{CO}_{2}$ inhalation does not activate the HPA axis. Nevertheless, a study carried out in healthy volunteers reported that a single inhalation of $35 \% \mathrm{CO}_{2}$ increased blood pressure and subjective fear, and activated the HPA axis (Bailey et al. 2003).

\section{COLECYSTOKININ AGONISTS}

Based on preclinical evidence indicating that the neuropeptide colecystokinin (CCK) played a role in anxiety, a pilot study has been conducted in panic patients with the tetrapeptide CCK-4, which readily crosses the blood-brain barrier (Bradwejn et al. 1990). All 11 patients that participated in the investigation panicked after the IV injection of $50 \mu \mathrm{g}$ of CCK-4, and none did so after placebo. The patients reported that the chemically-induced PA was similar to the real-life PA, except that they were more abrupt. They also resembled the PA induced by single inhalation of $35 \% \mathrm{CO}_{2}$ more than that induced by flumazenil. Although CCK-4 can induce a PA in healthy volunteers, PD patients are more susceptible to the panicogen; reported panic rates caused by 25 and $50 \mu \mathrm{g}$ of CCK-4 were 91 and $100 \%$, respectively in PD patients as compared to 17 and $47 \%$ in healthy volunteers (Bradwejn et al. 1991). The effect of CCK-4 is also antagonized by selective CCK-B antagonists, indicating that this type of CCK receptor mediates the panicogenic action of CCK-4. Further validating the CCK model of PA, it has been reported that pre-treatment with antipanic drugs, such as imipramine and fluoxetine antagonize CCK-4-induced PA (for a review, see Bourin et al. 1998). An interaction between CCK and BZD is indicated by reported results showing that viga- 
batrin, an inhibitor of the GABA-transaminase enzyme that metabolizes GABA as well as the BZD agonist and antipanic agent alprazolam attenuate the CCK-4-induced PA (Zwanzger et al. 2001, 2003). Overall, these results place CCK-4 at a high rank as a panicogenic agent.

Another CCK-B agonist, pentagastrin is less potent than CCK-4, but also induces PA (Abelson and Nesse 1990). Patients with PD are more susceptible to pentagastrin than healthy controls, the PA rate being proportional to the dose administered (van Megen et al. 1994).

We have found twelve articles investigating the HPA axis following CCK-B agonists, of which eight were with CCK-4 and four with pentagastrin. Despite differences in dosage (20-100 $\mu \mathrm{g}, 50 \mu \mathrm{g}$ being used in five studies) stress hormones (ACTH, cortisol or prolactin) increased after CCK-4, regardless of the subject experiencing a PA or not (Kellner et al. 1997, van Megen et al. 1997, Shlik et al. 1997, Flint et al. 2000, Strohle et al. 2000, Zwanzger et al. 2001, 2003). As an exception, however, van Megen et al. (1996) have reported no increase in either prolactin or cortisol in $12 \mathrm{PD}$ patients after administration of 25 e $50 \mu \mathrm{g}$ of CCK- 4 , the panic rates being $44 \%$ and $71 \%$, respectively. It is also worth remarking that Strohle et al. (2000) have described dissociation between ACTH and cortisol, only the former being elevated by CCK-4; larger ACTH increases occurred in those subjects who panicked.

Increases in ACTH and cortisol have also been reported following pentagastrin administration (Abelson et al. 1994, McCann et al. 1997, Khan et al. 2004). In contrast, the results of the study by van Megen et al. (1994), in which a range of doses from 0.1-0.6 $\mu \mathrm{g}$ of pentagastrin was administered, have shown a plasma cortisol reduction in both PD patients and normal controls, despite a panic rate of $55 \%$ being observed in the PD patients.

Since CCK-B agonists generally increase stress hormones regardless of the occurrence of a PA or not, it is likely that HPA activation represents a pharmacological action independent of the panicprovoking mechanism.

\section{FLUMAZENIL}

Benzodiazepine anxiolytics such as diazepam have been widely used to treat GAD during the 1970s and early 1980s. Research on their mechanism of action led to the identification of benzodiazepine receptors (BZR) in neuronal membranes, which modulate the action of the most ubiquitous inhibitory neurotransmitter $\gamma$-amino-butyric acid (GABA). Benzodiazepine anxiolytics acted as BZR agonists, since they increase the affinity of GABA for $\mathrm{GABA}_{\mathrm{A}}$ receptors, thereby intensifying the neurotransmitter action. In contrast, there are pharmacological agents that also bind to BZR, but decrease GABA affinity for the $\mathrm{GABA}_{A}$ receptor site, thus reducing the inhibitory action of the neurotransmitter. These agents have pharmacological effects that are opposite to those of the BZR agonists, that is, they enhance anxiety, decrease sleep and facilitate convulsions. For this reason, they have been named BZD inverse agonists. Flumazenil stands in a third category, since in spite of binding with high affinity to the BZR, the drug neither enhances nor weakens the action of GABA on $\mathrm{GABA}_{\mathrm{A}}$ receptors. As a result, flumazenil is generally ineffective when given alone, but antagonizes the effects of either BZR agonists or antagonists when previously administered and, thus, is classified as a BZR antagonist. Nevertheless, there are experimental conditions where flumazenil causes either an anxiolytic or an anxiogenic effect of its own. This phenomenon has been attributed to the interaction of flumazenil with an excess of endogenous BZR ligands or with altered BZD receptors, both changes being dependent on the degree of environmental stress (for a review, see Haefely and Hunkeler 1988).

With such preclinical profile, it was expected that flumazenil would neither enhance nor reduce anxiety in humans, at least in non-stressful conditions. This proved to be true in healthy volunteers and in several anxiety disorder patients. However, a large proportion of PD patients presented a PA following flumazenil administration (Nutt et al. 1990, Woods et al. 1991). This finding led to the sup- 
position that PD patients had a shift in the BZR "set point" toward an inverse agonist action of flumazenil (Nutt et al. 1990). This hypothesis spurred the use of flumazenil as an experimental tool for the study of PA.

We have found three articles reporting the effect of flumazenil on stress hormones. In the first one, conducted by Woods et al. (1991) two doses of flumazenil, 200 and $600 \mathrm{mg}$ were orally administered to the same patient at a one-week interval. This was preceded by one week of placebo plus psychotherapy treatment and 3 weekly sessions with placebo challenge. The PA was evaluated by two psychometric scales and three physiological measures: blood pressure, heart rate and electrocardiogram. Two hormonal assays were conducted, one for catecholamine metabolite methyl-hydroxyphenyl-glycol (MHPG), and the other for cortisol. The obtained results have shown that the lowest dose of flumazenil increased anticipatory anxiety and produced a PA in 4 out of 10 panic patients. However, the dose of $600 \mathrm{mg}$ was ineffective. In spite of this difference, no change in plasma cortisol occurred with either dose.

In the studies by Strohle et al. $(1998,1999)$ an IV bolus injection of $2 \mathrm{mg}$ of flumazenil (in $20 \mathrm{ml}$ saline injected within $1 \mathrm{~min}$ ) was given to PD patients and normal controls. No increase in either plasma cortisol or ACTH was found, not even in PD disorder patients that were sensitive to lactate. However, neither a PA nor an increase in anxiety were induced by flumazenil in either controls or PD patients, in disagreement with Nutt et al. (1990) and Woods et al. (1991) reports. These results weaken the status of flumazenil as a selective panicogen.

\section{YOHIMBINE}

Preclinical results have shown that stimulation of the LC induces anxiety-like behavior in monkeys. The LC is a brain stem nucleus that concentrates the cell bodies of noradrenaline (NA)-containing neurons, of which nerve fibers project to the forebrain. These findings have inspired theories about the role of NA in anxiety disorders, among which PD. To test these theories, drugs that block $\alpha_{2}$-adrenergic receptors have been used to stimulate ascending noradrenergic neurons in both laboratory animals and humans, since the firing rate of LC neurons is inhibited by such receptors. The most widely used is the alkaloid yohimbine. As expected, IV administration of this drug has been shown to induce a burst of anxiety peaking within $5 \mathrm{~min}$ from the end of the infusion, with symptoms resembling a PA. Patients with PD proved to be more sensitive to yohimbine than healthy controls as well as patients diagnosed with GAD or OCD. In addition, the anxiogenic effect of yohimbine is reduced by antipanic drug treatment (for a review, see Charney et al. 1987a). In spite of this suggestive evidence, the status of yohimbine as a selective model of PA has been questioned (see, e.g., Griez and Schruers 1998). It is likely that yohimbine is an anxiety-inducing rather than a panicogenic agent, PD patients being generally more sensitive to interoceptive changes than healthy subjects.

We have found in the literature three studies on yohimbine and stress hormones. The same procedure was used in both cases: $20 \mathrm{mg}$ or the drug or placebo given orally to PD patients and normal controls in experimental sessions held one week apart, psychological and physiological measures, including plasma cortisol, being taken to assess the pharmacological effects. The obtained results have consistently shown an increase in anxiety and in cortisol, indicating HPA axis activation (Charney et al. 1987a, Albus et al. 1992, Gurguis et al. 1997). Nevertheless, only in the first study changes identified as a PA occurred after yohimbine, 54\% in PD patients and $5 \%$ in controls, respectively (Charney et al. 1987a).

\section{SEROTONINERGIC AGENTS}

The effectiveness of selective serotonin reuptake inhibitors (SSRI) in the treatment of PD highlights the importance of serotonin (5-HT) in this disorder (Graeff 1997). An early view postulated that $5-\mathrm{HT}_{2}$ receptors would by supersensitive in PD. To test this hypothesis, drugs that stimulate 
5- $\mathrm{HT}_{2}$ receptors either directly (direct agonists) or through endogenous 5-HT (indirect agonists) have been used. Among the direct agonists stands 1-(mchlorophenyl) piperazine (mCPP). This compound binds to several $5-\mathrm{HT}_{1}$ and $5-\mathrm{HT}_{2}$ receptors, but has preferential affinity for the $5-\mathrm{HT}_{2 \mathrm{C}}$ subtype (Charney et al. 1987b). However, the 5-HT 2 receptor supersensitivity hypothesis of PD has not been supported by the results of clinical trials in which the 5- $\mathrm{HT}_{2}$ antagonist ritanserin was assayed in PD patients. Contrary to the expectations, the drug treatment not only failed to improve the patients' symptoms, but tended to aggravate them (Graeff 1997). Indeed, these results together with a wealth of preclinical and human experimental results constituted the data basis for the alternative view that ascribes to 5- $\mathrm{HT}_{1}$ and $5-\mathrm{HT}_{2}$ receptors localized in the midbrain periaqueductal gray an inhibitory action on the PA. In turn, stimulation of 5- $\mathrm{HT}_{2}$ receptors placed in the amygdala and other forebrain structures would enhance anticipatory anxiety (Deakin and Graeff 1991, Graeff 2004). Within this perspective, mCPP would be an anxiogenic, rather than a panicogenic agent.

Eight articles on mCPP and stress hormones have been found. In six of them, the intravenous route was used in all cases, but there was a wide range of doses, from 0.05 to $0.5 \mathrm{mg} / \mathrm{kg}$, given through either a rapid injection or an infusion made along several minutes. In addition to psychometric measures, plasma cortisol and, in five cases, plasma prolactin as well have been measured. In spite of these differences, the results have concurred in showing an increase of stress hormones after mCPP (Charney et al. 1987b, Kahn et al. 1988, Klein et al. 1991, Germine et al. 1994, Wetzler et al. 1996, Benjamin et al. 1997). In the remaining two studies the oral route was used. Asnis et al. (1992) gave $0.25 \mathrm{mg} / \mathrm{kg} \mathrm{mCPP}$ to normal controls as well as patients with PD and major depression, and in the three groups plasma cortisol was similarly increased. The only negative result was reported by Broocks et al. (2000), after $0.4 \mathrm{mg} / \mathrm{kg}$ of mCPP, PO; despite the fact that $55 \%$ of PD patients presented attacks versus none in controls, no significant in- crease in cortisol, ACTH or prolactin occurred in either group, although there was a trend to a cortisol increase in panic patients.

Another serotonergic tool that has been used in panic patients is fenfluramine. This drug promotes the release of 5-HT from nerve endings and inhibits its reuptake across the neuronal membrane. As a result, the post-synaptic concentration of 5-HT is increased, resulting in overstimulation of the neighbouring receptors (Graeff 1997). Therefore, fenfluramine acts as an indirect 5-HT agonist. The results of controlled assays have shown that fenfluramine is anxiogenic in PD patients, but the kind of anxiety it produces resembles a wave of anticipatory anxiety rather than a PA (Targum and Marshall 1989). In addition, chronic administration of fenfluramine has been shown to ameliorate PD (Solyom 1994, Hetem 1995). A stringent test of whether fenfluramine is an anxiogenic or a panicogenic agent has been performed by Mortimore and Anderson (2000). They administered the drug before $\mathrm{CO}_{2}$ challenge in $\mathrm{PD}$ patients and found that the panic symptoms were attenuated whereas anticipatory anxiety occurring before the challenge was augmented. This evidence questions the validity of the fenfluramine challenge as a panic model. Instead, the drug appears to enhance anticipatory anxiety.

Four studies have been performed in which the action of fenfluramine on the HPA axis was assessed. The two earlier studies included patients with a diagnosis of major depressive disorder in addition to PD patients and normal controls; $60 \mathrm{mg}$ of fenfluramine, PO, were taken and both plasma cortisol and prolactin were measured, besides the application of an anxiety rating scale. The obtained results have shown an increase of anxiety, cortisol and prolactin after the fenfluramine challenge (Targum and Marshall 1989, Targum 1990). A later study by Targum (1992) compared 12 PD patients with 8 normal controls in regard to their response to orally administered fenfluramine. Only in the patients, an anxiogenic response was observed. Patients also showed a greater increase in plasma cortisol than controls; in contrast there was no difference between 
groups as to the cortisol response to lactate. The conclusion was drawn that these challenges stimulate different neurobiological mechanisms and that the fenfluramine-precipitated anxiety is more akin to anticipatory or generalized anxiety than to the true panic attack. Nevertheless, the results of a similar study by Judd et al. (1994) have shown no significant difference between PD patients and controls in both the cortisol and prolactin responses to fenfluramine.

An additional way to increase the action of endogenous 5-HT is to increase its biosynthesis by administering the precursor 5-hydroxytryptophan (5-HTP). However, this method is not very selective, since 5-HTP is also uptaken by noradrenergic neurons where it promotes NA release (Graeff 1997).

In this survey, four reported studies with 5-HTP were found. In two of them $60 \mathrm{mg}$ of L-5-HTP have been infused into the vein for $30 \mathrm{~min}$ and plasma cortisol was measured to assess HPA functioning (Westenberg and den Boer 1989, den Boer and Westenberg 1990). In both studies cortisol was increased, in spite of the subjects reporting no change in anxiety. In the third study, $200 \mathrm{mg}$ of same drug were orally administered, and salivary cortisol was assayed (Schruers et al. 2002). A similar increase in cortisol was observed after 5-HTP ingestion in both PD patients and controls, testifying against the 5HT receptor supersensitivity hypothesis of PD mentioned above. Lower doses of 5-HTP (10-40 mg, IV) have been used by Van Vliet et al. (1996) that did not increase anxiety or induce PA in either PD patients or normal controls; the highest dose caused an increase in plasma cortisol that was higher in patients than in controls only at $30 \mathrm{~min}$ after the drug infusion.

In synthesis, the above evidence consistently shows that stimulation of 5-HT receptors, either directly or indirectly, activates the HPA axis. However this happens in both healthy subjects and PD patients, and regardless of whether anxiety or a PA occurs. Therefore, HPA activation seems to be to a direct effect of these drugs on the HPA axis, independent of behavioral change.

\section{CAFFEINE}

Caffeine is a widely used psychostimulant agent, and it is well known that high doses of the drug increase anxiety and impair sleep. Charney et al. (1985) have shown that PD patients are more susceptible to the alkaloid than normal controls, $71 \%$ of the patients presenting a PA following the injection of $10 \mathrm{mg} / \mathrm{kg}$ of caffeine citrate. The results of this study have further shown that caffeine increased plasma cortisol in patients as well as in normal controls. In another study carried out in PD patients, Klein et al. (1991) reported that $0.5 \mathrm{mg} / \mathrm{kg} \mathrm{m}-\mathrm{CPP}$ and $480 \mathrm{mg}$ caffeine had significantly greater anxiogenic and panic-inducing effects than placebo and produced equivalent increases in plasma cortisol, but only m-CPP increased plasma prolactin.

\section{CONCLUSIONS AND FINAL REMARKS}

The results on the effect of panicogenic agents on HPA functioning reviewed above are summarized in Table I.

\section{TABLE I}

Action of panicogenic agents on the hypothalamicpituitary-adrenal (HPA) axis.

\begin{tabular}{l|c|l}
\hline $\begin{array}{c}\text { Panicogenic } \\
\text { agent }\end{array}$ & $\begin{array}{c}\text { Number of } \\
\text { studies }\end{array}$ & $\begin{array}{c}\text { HPA axis } \\
\text { activity }\end{array}$ \\
\hline Lactate & 10 & Unchanged \\
\hline $\mathrm{CO}_{2}$ & 4 & Unchanged \\
\hline $\mathrm{CCK}-4$ & 7 & Activation \\
CCK-4 & 1 & Unchanged \\
Pentagastrin & 3 & Activation \\
& 1 & Unchanged \\
\hline Flumazenil & 3 & Unchanged \\
\hline Yohimbine & 3 & Activation \\
\hline mCPP & 7 & Activation \\
& 1 & Unchanged \\
Fenfluramine & 4 & Activation \\
\hline Caffeine & 2 & Activation \\
\hline
\end{tabular}

In view of evidence discussed above, the following conclusions may be drawn: 
1. The results of two out of three reported studies on real-life PA (not presented in Table I) have shown no change in HPA function. The HPA activation found in the remaining study may be due to the anticipatory anxiety generated by the procedure of collecting salivary samples for assaying cortisol.

2. The most selective panicogenic agents, sodium lactate and $\mathrm{CO}_{2}$ did not activate the HPA axis.

3. CCK-B receptor agonists fulfill most of the criteria for a selective panicogen, but increased stress hormones. However, their action on the HPA axis seems to be independent from the panic-inducing mechanism.

4. The benzodiazepine receptor antagonist flumazenil does not activate the HPA axis. Nevertheless, flumazenil does not reliably induce panic attacks in PD patients.

5. The remaining agents listed in Table I - the $\alpha_{2}$ antagonist yohimbine, the serotonergic agents $\mathrm{mCPP}$ and fenfluramine, as well as the psychostimulant caffeine - consistently activate the HPA axis. However, these agents induce anxiety in both PD patients and normal controls, although the former are more susceptible than the latter. Therefore, they are nonselective panicogenic agents. The 5-HT synthesis precursor, 5-HTP, also activates the HPA axis, but does not induce anxiety in either PD patients or controls.

Briefly, the available evidence indicates that the PA that occurs in real-life situations or is triggered by selective panicogens does not activate the HPA axis. In contrast, nonselective agents that induce anticipatory anxiety rather than a true PA increase the release of stress hormones.

This conclusion is supported by the results of two studies that used experimental models related to panic. The first one has been conducted in our laboratory with an experimental procedure designed to induce anxiety in human subjects, the Simulated Public Speaking (SPS) test. In this procedure, the subject is requested to prepare a speech and then speak in front of a videocamera, his/her performance being recorded on videotape. At different stages of the experimental session, the subject fills selfevaluation rating scales that measure anxiety and other subjective states. In addition, physiological measures, such as heart rate, blood pressure and electrical skin conductance may be recorded (McNair et al. 1982, Guimarães et al. 1987). Epidemiological as well as pharmacological evidence reviewed elsewhere (Graeff et al. 2003, Graeff 2004) led to the hypothesis that SPS mobilizes the same neural networks that are involved in the PA. In particular, the periaqueductal gray matter (PAG) of the midbrain, which is critical for integrating defensive reactions to proximal threat, has been implicated in PD.

If the brain mechanisms involved in SPS and in the PA were the same, and the PA does not activate the HPA axis, SPS should not increase cortisol. To test this prediction, Garcia-Leal et al. (2004) have assayed salivary cortisol in three groups of subjects before and after SPS. The first group consisted of 18 symptomatic panic patients, the second of 16 nonsymptomatic patients under drug treatment, and the third of 17 healthy controls. The obtained results have shown that the level of cortisol was high at the beginning of the experimental session, correlating with the rise in anticipatory anxiety that the subject presents as a function of the novelty and potential risk of the experimental situation. The cortisol level decreased along the next $70 \mathrm{~min}$, as the subject became adapted to the experimental situation, and the anxiety index declined. Preparation and performance of speech raised the anxiety score to the initial level or above, but failed to increase salivary cortisol during the 60 -min period that followed the speech in the three experimental groups. The last result indicates that SPS does not activate the HPA axis in the same way as the PA.

The second is a study with electrical stimulation of the rat PAG, which has been conducted at Luiz Schenberg's laboratory, in Vitória, ES, Brazil. The dorsal PAG stimulation elicits defensive reac- 
tions, like running and jumping that have been related to panic (Schenberg et al. 2001). In spite of its marked aversive properties, PAG stimulation did not increase plasma levels of the stress hormones ACTH and prolactin (Vargas et al. 2001).

From a wider perspective, the reviewed evidence indicating that the PA does not activate the HPA axis, in contrast to anticipatory anxiety, supports hypotheses that conceptualize anxiety and panic as distinct emotional states controlled by specific neurobiological mechanisms. In this regard, Deakin and Graeff (1991) have distinguished anticipatory anxiety in response to conditioned aversive stimuli from the panic-like reactions (freezing, fleeing or fighting) to pain, asphyxia or proximal danger stimuli. The anatomical basis of anticipatory anxiety would be the septo-hippocampal system, the amygdala and prefrontal cortical areas, whereas panic would be integrated by a longitudinallyorganized system comprising the amygdala, medial hypothalamus and mesencephalic PAG (for a critical discussion, see McNaughton and Corr 2004). In terms of the stress concept, it may be said that anticipatory anxiety constitutes the psychological counterpart of Selye's "general adaptation syndrome" (Selye 1936), whereas the PA would engage the same brain mechanisms that command Cannon's "emergency response" (Cannon 1914). The first process activates the HPA axis releasing corticoid hormones, whereas the second stimulates the sympathetic division of neurovegetative nervous system, thus releasing catecholamines.

\section{ACKNOWLEDGMENTS}

This work was supported by a grant from the Fundação de Amparo à Pesquisa do Estado de São Paulo (FAPESP, 2002/13197-2). FGG is recipient of research fellowships from the Conselho Nacional de Desenvolvimento Cientifico e Tecnológico (CNPq) and Fundação de Amparo à Pesquisa, Ensino e Assistência do Hospital das Clínicas da Faculdade de Medicina de Ribeirão Preto (FAEPA). We are indebted to Heloísa E.G. de Oliveira Graeff for revision of English writing.

\section{RESUMO}

Realizou-se levantamento bibliográfico no indexador MEDLINE, através das palavras-chave "cortisol" e "panic", sem limite de tempo, restringindo-se a seres humanos e à localização das palavras-chave no título e no resumo. Foram excluídos artigos de revisão e relatos de caso, estudos sobre alterações ocorridas entre dois ataques, e os que tratavam de outras doenças psiquiátricas ou de sujeitos sadios, quando não comparados com pacientes de pânico. Os resultados mostraram que ataques de pânico naturais ou provocados pelos agentes panicogênicos seletivos, lactato de sódio e dióxido de carbono, não ativam o eixo hipotálamo-pituitária-adrenal (HPA). Agonistas do receptor de colecistocinina B elevam os hormônios de estresse, quer haja ataque de pânico ou não, parecendo ativar diretamente o eixo HPA. O antagonista benzodiazepínico flumazenil não eleva o nível dos hormônios de estresse, porém não induz ataques de pânico de modo consistente. Agentes farmacológicos que produzem ansiedade em pacientes de pânico e em voluntários saudáveis elevam o nível dos hormônios de estresse, entre estes o antagonista $\alpha_{2}$-adrenérgico ioimbina, os agentes serotonérgicos 1-(m-clorofenil) piperazina (mCPP) e fenfluramina, bem como o agente psicostimulante cafeína. Portanto, o ataque de pânico não parece ativar o eixo HPA, ao contrário da ansiedade antecipatória.

Palavras-chave: hormônios de estresse, ataque de pânico, ansiedade.

\section{REFERENCES}

Abelson JL And Nesse RM. 1990. Cholecystokinin-4 and panic. Arch Gen Psychiatry 47: 395.

Abelson JL, Nesse RM and ViniK AI. 1994. Pentagastrin infusions in patients with panic disorder. II. Neuroendocrinology. Biol Psychiatry 36: 84-96.

Albus M, Zahn TP And Breier A. 1992. Anxiogenic properties of yohimbine. I. Behavioral, physiological and biochemical measures. Eur Arch Psychiatry Clin Neurosci 241: 337-344.

American Psychiatry Association. 1980. Diagnostic and statistical manual of mental disorders, $3^{\text {rd }}$ ed., Washington, DC: American Psychiatric Association Press, 756 p.

American Psychiatric Association. 1994. Diagnostic and statistical manual of mental disorders, $4^{\text {th }}$ ed., Washington, DC: American Psychiatric Association Press, 886 p. 
ANTONI FA. 1993. Vasopressinergic control of pituitary adrenocorticotropin secretion comes of age. Front Neuroendocrinol 14: 76-122.

Asnis GM, Wetzler S, Sanderson WC, Kahn RS AND VAN PraAg HM. 1992. Functional interrelationship of serotonin and norepinephrine: cortisol response to MCPP and DMI in patients with panic disorder, patients with depression, and normal controls. Psychiatry Res 43: 65-76.

Bailey JE, Argyropoulos SV, Lightman SL and NutT DJ. 2003. Does the brain noradrenaline network mediate the effects of the $\mathrm{CO}_{2}$ challenge? J Psychopharmacol 17: 252-259.

Bandelow B, Wedekind D, Pauls J, Broocks A, HaJAK G AND RÜther E. 2000. Salivary cortisol in panic attacks. Am J Psychiatry 157: 454-456.

Benjamin J, Nemetz H, Fux M, Bleichman I and AgAm G. 1997. Acute inositol does not attenuate $\mathrm{m}$-CPP-induced anxiety, mydriasis and endocrine effects in panic disorder. J Psychiatr Res 31: 489495.

Bourin M, Baker GB and Bradwejn J. 1998. Neurobiology of panic disorder. J Psychosom Res 44: 163-180.

Bradwejn J, Koszycki D and Meterissian G. 1990. Cholecystokinin-tetrapeptide induces panic attacks in patients with panic disorder. Can J Psychiatry 35: 83-85.

Bradwejn J, Koszycki D and Shriqui C. 1991. Enhanced sensitivity to cholecystokinin-tetrapeptide in panic disorder. Clinical and behavioral findings. Arch Gen Psychiatry 48: 603-610.

Broocks A ET AL. 2000. Increased psychological responses and divergent neuroendocrine responses to $\mathrm{m}$-CPP and ipsapirone in patients with panic disorder. Int Clin Psychopharmacol 15: 153-161.

Cameron OG, Lee MA, Curtis GC and McCann DS. 1987. Endocrine and physiological changes during "spontaneous" panic attacks. Psychoneuroendocrinol 12: 321-331.

Cannon WB. 1914. The emergency function of the adrenal medulla in pain and the major emotions. Am J Physiol 33: 356-372.

Carr DB, Sheehan DV, Surman OS, Coleman JH, Greenblatt DJ, Heninger GR, Jones KJ, Levine PH AND WATKINS WD. 1986. Neuroendocrine cor- relates of lactate-induced anxiety and their response to chronic alprazolam therapy. Am J Psychiatry 143: 483-494.

Charney DS, Heninger GR and Jatlow PI. 1985. Increased anxiogenic effects of caffeine in panic disorders. Arch Gen Psychiatry 42: 233-243.

Charney DS, Woods SW, Goodman WK and HeninGER GR. 1987a. Neurobiological mechanisms of panic anxiety: biochemical and behavioral correlates of yohimbine-induced panic attacks. Am J Psychiatry 144: 1030-1036.

Charney DS, Woods SW, Goodman WK and HeninGER GR. 1987b. Serotonin function in anxiety. II. Effects of the serotonin agonist MCPP in panic disorder patients and healthy subjects. Psychopharmacol 92: 14-24.

Coplan JD, Goetz R, Klein DF, Papp LA, Fyer AJ, Liebowitz MR, Davies SO ANd GoRMAn JM. 1998. Plasma cortisol concentrations preceding lactateinduced panic: psychological, biochemical, and physiological correlates. Arch Gen Psychiatry 55: 130-136.

DEAKIN JFW AND GRAEFF FG. 1991. 5-HT and mechanisms of defence. J Psychopharmacol 5: 305-315.

Den Boer JA And Westenberg HG. 1990. Behavioral, neuroendocrine, and biochemical effects of 5hydroxytryptophan administration in panic disorder. Psychiatry Res 31: 267-278.

Flint AJ, Koszycki D, Bradwejn J and Vaccarino FJ. 2000. Neurohormonal responses to cholecystokinin tetrapeptide: a comparison of younger and older healthy subjects. Psychoneuroendocrinol 25: 633-647.

Garcia-Leal C, Parente ACBV, Del-Ben CM, GuimaRÃes FS, Moreira AC, Elias LLK and GraefF FG. 2004. Anxiety and salivary cortisol in symptomatic and nonsymptomatic panic patients and healthy volunteers performing simulated public speaking. Psychiatry Res 133: 239-252.

Germine M, Goddard AW, Sholomskas DE, Woods SW, Charney DS and Heninger GR. 1994. Response to meta-chlorophenylpiperazine in panic disorder patients and healthy subjects: influence of reduction in intravenous dosage. Psychiatry Res 54: 115-133. 
Gorman JM, Askanazi J, Liebowitz MR, Fyer AJ, Stein J, Kinney JM and Klein DF. 1984. Response to hyperventilation in a group of patients with panic disorder. Am J Psychiatry 141: 857-861.

Graeff FG. 1997. Serotonergic systems. Psychiat Clin N Am 20:723-739.

GraefF FG. 2004. Serotonin, the periaqueductal gray and panic disorder. Neurosci Biobehav Rev 28: 239-259.

Graeff FG, Parente A, Del-Ben CM and Guimarães FS. 2003. Pharmacology of human experimental anxiety. Braz J Med Biol Res 36: 421-432.

Griez E AND Schruers K. 1998. Experimental pathophysiology of panic. J Psychosom Res 45: 493-503.

Guimarães FS, Zuardi AW and GraefF FG. 1987. Effect of chlorimipramine and maprotiline on experimental anxiety in humans. J Psychopharmacol 1: 184-192.

Gurguis GN, Vitton BJ and Uhde TW. 1997. Behavioral, sympathetic and adrenocortical responses to yohimbine in panic disorder patients and normal controls. Psychiatry Res 71: 27-39.

Haefely WE and Hunkeler W. 1988. The story of flumazenil. Eur J Anesthesiol Suppl 2: 3-13.

Hetem LAB. 1995. Addition of d-fenfluramine to benzodiazepines produced a marked improvement in refractory panic disorder - a case report. J Clin Psychopharmacol 16: 77-78.

Hollander E, Liebowitz MR, Gorman JM, Cohen B, Fyer A ANd Klein DF. 1989. Cortisol and sodium lactate-induced panic. Arch Gen Psychiatry 46: 135-140.

Judd FK, Apostolopoulos M, Burrows GD AND NORMAN TR. 1994. Serotonergic function in panic disorder: endocrine responses to D-fenfluramine. Prog Neuropsychopharmacol Biol Psychiatry 18: 329-337.

Kahn RS, Asnis GM, Wetzler S and van Praag HM. 1988. Neuroendocrine evidence for serotonin receptor hypersensitivity in panic disorder. Psychopharmacol 96: 360-364.

Kellner M, Wiedemann K and Holsboer F. 1992. Atrial natriuretic factor inhibits the $\mathrm{CRH}$-stimulated secretion of ACTH and cortisol in man. Life Sci 50: 1835-1842.

Kellner M, Herzog L, Yassouridis A, Holsboer F
AND Wiedemann K. 1995. Possible role of atrial natriuretic hormone in pituitary-adrenocortical unresponsiveness in lactate-induced panic. Am J Psychiatry 152: 1365-1367.

Kellner M, Yassouridis A, Jahn H and Wiedemann K. 1997. Influence of clonidine on psychopathological, endocrine and respiratory effects of cholecystokinin tetrapeptide in patients with panic disorder. Psychopharmacol 133: 55-61.

Kellner M, Knaudt K, Jahn H, Holsboer F and WiEdEMANN K. 1998. Atrial natriuretic hormone in lactate-induced panic attacks: mode of release and endocrine and pathophysiological consequences. J Psychiatry Res 32: 37-48.

Khan S, Liberzon I and Abelson JL. 2004. Effects of propranolol on symptom and endocrine responses to pentagastrin. Psychoneuroendocrinol 29: $1163-$ 1171.

KLEIN DF. 1993. False suffocation alarms, spontaneous panics and related conditions. An integrative hypothesis. Arch Gen Psychiatry 50: 306-317.

Klein E, Zohar J, Geraci MF, Murphy DL and Uhde TW. 1991. Anxiogenic effects of m-CPP in patients with panic disorder: comparison to caffeine's anxiogenic effects. Biol Psychiatry 30: 973-984.

Levin AP, Doran AR, Liebowitz MR, Fyer AJ, GoRMAN JM, KLeIN DF AND PAul SM. 1987. Pituitary adrenocortical unresponsiveness in lactate-induced panic. Psychiatry Res 21: 23-32.

LIEBOwITZ MR ET AL. 1985. Lactate provocation of panic attacks. II. Biochemical and physiological findings. Arch Gen Psychiatry 42: 709-719.

Maddock RJ, Carter CS and Gietzen DW. 1991. Elevated serum lactate associated with panic attacks induced by hyperventilation. Psychiatry Res 38: 301-311.

Mason JW. 1975. A historical review of stress. J Hum Stress 1: 6-12.

McCann UD, Slate SO, Geraci M, Roscow-Terrill D AND UhDE TW. 1997. A comparison of the effects of intravenous pentagastrin on patients with social phobia, panic disorder and healthy controls. Neuropsychopharmacol 16: 229-237.

McEwen BS. 2000. The neurobiology of stress: from serendipity to clinical relevance. Brain Res 886: 172-189. 
McNair DM, Frankenthaler LM, Czerlinsky T, White TW, SAsson S AND Fisher S. 1982. Simulated public speaking as a model of clinical anxiety. Psychopharmacol 77: 7-10.

McNaughton N ANd Corr PJ. 2004. A two-dimensional neuropsychology of defense: fear / anxiety and defensive distance. Neurosci Biobehav Rev 28: 285-305.

Mortimore C And Anderson IM. 2000. d-Fenfluramine in panic disorder: a dual role for 5-hydroxytryptamine. Psychopharmacol 149: 251-258.

Nutt DJ, Glue P, Lawson C AND Wilson S. 1990 Flumazenil provocation of panic attacks Evidence for altered benzodiazepine receptor sensitivity in panic disorder. Arch Gen Psychiatry 47: 917-925.

Peskind ER, Jensen CF, Pascualy M, Tsuang D, CowLEY D, MarTin DC, Wilkinson CW AND RASKind MA. 1998. Sodium lactate and hypertonic sodium chloride induce equivalent panic incidence, panic symptoms, and hypernatremia in panic disorder. Biol Psychiatry 44: 1007-1016.

Pitts FN AND McClure JN. 1967. Lactate metabolism in anxiety neurosis. N Engl J Med 277: 1329-1336.

Sasaki I, Akiyoshi J, Sakurai R, Tsutsumi T, Ono H, Yamada K and FujiI I. 1996. Carbon dioxide induced panic attack in panic disorder in Japan. Prog Neuropsychopharmacol Biol Psychiatry 20: 1145 1157.

Schenberg LC, Bittencourt AS, Sudré ECM AND VARGAs LC. 2001. Modeling panic attacks. Neurosci Biobehav Rev 25: 647-659.

Schruers K, van Dienst R, Nicolson N AND Griez E. 2002. L-5-hydroxytryptophan induced increase in salivary cortisol in panic patients and healthy volunteers. Psychopharmacol 161: 365-369.

Seier FE, Kellner M, Yassouridis A, Heese R, Strian F and Wiedemann K. 1997. Autonomic reactivity and hormonal secretion in lactate-induced panic attacks. Am J Physiol 272: 2630-2638.

Selye H. 1936. A syndrome produced by diverse nocuous agents. Nature 138: 32.

Shlik J, Aluoja A, Vasar V, Vasar E, Podar T and BRADWEJN J. 1997. Effects of citalopram treatment on behavioural, cardiovascular and neuroendocrine response to cholecystokinin tetrapeptide challenge in patients with panic disorder. J Psychiatry Neurosci 22: $332-340$.
Sinha SS, Coplan JD, Pine DS, Martinez JA, KLein DF AND Gorman JM. 1999. Panic induced by carbon dioxide inhalation and lack of hypothalamicpituitary-adrenal axis activation. Psychiatry Res 86 : 93-98.

Solyom L. 1994. Controlling panic attacks with fenfluramine. Am J Psychiatry 151: 621-622.

Strohle A, Kellner M, Yassouridis A, Holsboer F AND WiEDEMANN K. 1998. Effect of flumazenil in lactate-sensitive patients with panic disorder. Am J Psychiatry 155: 610-612.

Strohle A, Kellner M, Holsboer F and Wiedemann K. 1999. Behavioral, neuroendocrine, and cardiovascular response to flumazenil: no evidence for an altered benzodiazepine receptor sensitivity in panic disorder. Biol Psychiatry 45: 321-326.

Strohle A, Holsboer F and Rupprecht R. 2000. Increased ACTH concentrations associated with cholecystokinin tetrapeptide-induced panic attacks in patients with panic disorder. Neuropsychopharmacol 22: $251-256$.

TARgum SD. 1990. Differential responses to anxiogenic challenge studies in patients with major depressive disorder and panic disorder. Biol Psychiatry 28: 21-34.

TARGum SD. 1992. Cortisol response during different anxiogenic challenges in panic disorder patients. Psychoneuroendocrinol 17: 453-458.

Targum SD and Marshall LE. 1989. Fenfluramine provocation of anxiety in patients with panic disorder. Psychiatry Res 28: 295-306.

VAN DE KAR LD AND BLAIR ML. 1999. Forebrain pathways mediating stress-induced hormone secretion. Front Neuroendocrinol 20: 1-48.

VAN DEN Hout MA AND Griez E. 1984. Panic symptoms after the inhalation of carbon dioxide. $\mathrm{Br}$ J Psychiatry 144: 503-507.

van Duinen MA, Schruers KR, Jaegers E, Maes M AND GRIEZ EJ. 2004. Salivary cortisol in panic: are males more vulnerable? Neuro Endocrinol Lett 25: 386-390.

van Megen HJ, Westenberg HG, den Boer JA, Haigh RM and Traub M. 1994. Pentagastrin induced panic attacks: enhanced sensitivity in panic disorder patients. Psychopharmacol 114: 449-455. 
van Megen HJ, Westenberg HG, den Boer JA and KAHN RS. 1996. The panic-inducing properties of the cholecystokinin tetrapeptide CCK4 in patients with panic disorder. Eur Neuropsychopharmacol 6: 187-194.

van Megen HJ, Westenberg HG, den Boer JA, Slaap B, van Es-Radhakishun F and Pande AC. 1997. The cholecystokinin-B receptor antagonist CI-988 failed to affect CCK-4 induced symptoms in panic disorder patients. Psychopharmacol 129: 243-248.

van Vliet IM, Slaap BR, Westenberg HG and den BOER JA. 1996. Behavioral, neuroendocrine and biochemical effects of different doses of 5-HTP in panic disorder. Eur Neuropsychopharmacol 6: 103-110.

Vargas LC, Silva SR, Reis AM, Tufik S, Carobrez AP AND Schenberg LC. 2001. Pharmacological and endocrinological properties of intracraniallyinduced panic-like behaviors. Soc Neurosci Abstr 27: 858.11.

Westenberg HG ANd den Boer JA. 1989. Serotonin function in panic disorder: effect of 1-5-hydroxytryptophan in patients and controls. Psychopharmacol 98: 283-285.

Wetzler S, Asnis GM, Delecuona JM and Kalus O. 1996. Serotonin function in panic disorder: intravenous administration of meta-chlorophenylpiperazine. Psychiatry Res 64: 77-82.

Woods SW, Charney DS, McPherson CA, Gradman AH and Heninger GR. 1987. Situational panic attacks. Behavioral, physiologic, and biochemical characterization. Arch Gen Psychiatry 44: 365-375.
Woods SW, Charney DS, Goodman WK and HeninGER GR. 1988. Carbon dioxide induced anxiety: behavioral, physiologic, and biochemical effects of carbon dioxide in patients with panic disorders and healthy subjects. Arch Gen Psychiatry 45: 43-52.

Woods SW, Charney DS, Silver JM, Krystal JH and Heninger GR. 1991. Behavioral, biochemical and cardiovascular responses to the benzodiazepine receptor antagonist flumazenil in panic disorder. Psychiatry Res 36: 115-127.

World Health Organization. 1992. The ICD-10 classification of mental and behavioral disorders. Clinical descriptions and diagnostic guidelines. Geneva, 351 p.

Zwanzger P, Baghai TC, Schuele C, Strohle A, Padberg F, Kathmann N, Schwarz M, Moller HJ AND RuPPRECHT R. 2001. Vigabatrin decreases cholecystokinin-tetrapeptide (CCK-4) induced panic in healthy volunteers. Neuropsychopharmacol 25: 699-703.

Zwanzger P, Eser D, Aicher S, Schule C, Baghai TC, Padberg F, Ella R, Moller HJ AND Rupprecht R. 2003. Effects of alprazolam on cholecystokinin-tetrapeptide-induced panic and hypothalamic-pituitary-adrenal-axis activity: a placebo-controlled study. Neuropsychopharmacol 28: 979-984. 